\title{
REDESCRIPTION OF FOUR SPECIES OF MEHDIELLA FROM TESTUDINIDAE, WITH A KEY TO THE SPECIES AND DISCUSSION ON THE RELATIONSHIPS AMONG THE SPECIES OF THIS GENUS
}

\author{
BOUAMER S.*, MORAND S.** \& KARA M.****
}

\section{Summary:}

Four species of the genus Mehdiella Seurat, 1918 are redescribed: M. cristata Petter, 1966 and M. stylosa dollfusi Petter, 1966, parasite of Pyxix arachnoides Bell, 1827 from Madagascar, M. s. stylosa (Thapar, 1925) and M. uncinata (Drasche, 1884), parasite of Testudo graeca Linneaus, 1758 Testudo hermanni Gmelin, 1789 and Testudo horsfieldii (Gray, 1844) from Palaearctic region. Light microscopy and scanning electron microscopy (SEM) studies revealed new informations on the morphology of these species. On the basis of this morphological study, the sub-species Mehdiella stylosa dollfusi and M. s. stylosa are raised to level of species. The position of Mehdiella cristata among the species of the genus Mehdiella and the relationships among the species of the genus Mehdiella are discussed. A key to the eight valid species Mehdiella is given.

KEY WORDS : Oxyurida, Mehdiella, Testudinidae, Palæarctic, Madagascar SEM, redescription, relationships, key of determination.
Résumé : Redescription de Quatre espèces de MEHDifila DE TESTUDINIDAE, AVEC UNE ClÉ DE DÉTERMINATION DE TOUTES LES ESPËCES DU GENRE MFHDIELLA

Quatre espèces du genre Mehdiella Seurat, 1918 sont redécrites: M. cristata Petter, 1966 et M. stylosa dollfusi Petter, 1966 parasites de Pyxix arachnoides Bell, 1827 de Madagascar, M. s. stylosa (Thapar, 1925) et M. uncinata (Drasche, 1884). parasites de Testudo graeca Linneaus, 1758, Testudo hermanni Gmelin, 1789 et Testudo horsfieldii (Gray, 1844) de la région paléarctique. L'utilisation du microscope photonique et du microscope électronique à balayage (MEB) fournit de nouvelles informations sur la morphologie des ces espèces. En se basant sur ces nouvelles données morphologiques, les sous-espèces Mehdiella stylosa dollfusi et M. s. stylosa, sont élevées au rang d'espèces. La position de Mehdiella cristata Petter, 1966 au sein du genre est discutée ainsi que les relations morphologiques entre les espèces de ce genre. Une clé de détermination de toutes les espèces du genre Mehdiella est donnée.

MOTS CLÉS: Oxyurida, Mehdiella, Testudinidae, paléarctique, Madagascar $M E B$, redescription, relations, clé de détermination.

site of Pyxis arachnoides Bell, 1827 from Madagascar and M. s. stylosa parasite of Testudo graeca Linneaus, 1758 from Palaearctic region. Isfan (1972) described M. dobrogicus Isfan, 1972 parasite of $T$. graeca from Italy; we question the validity of this species with its diagnosis based only on the description of the females. Bouamer et al. (2001b) revised the genus and described the species M. petterae Bouamer et al., 2001.

This paper is the second part of a redescription of the species of Mehdiella and complemens a revision of oxyuroids in Palaearctic tortoises (Bouamer \& Morand, 2000, Bouamer et al, 2001a and Bouamer et al., 2001b, Bouamer \& Morand, 2002). We give redescriptions of four species $M$. cristata, $M$. dollfusi, $M$. stylosa and M. uncinata and a key of determination to all species

\footnotetext{
* Centre de biologie et d'écologie tropicale et méditerranéenne, Laboratoire de biologie animale (UMR 5555 CNRS), Université de Perpignan, 52, avenue de Villeneuve, 66860 Perpignan, France.

** Centre de biologie et de gestion des populations (CBGP), Campus international de Baillarguet, CS 30016, 34988 Montferrier-sur-Lez Cedex, France.

*** Kafkas University, Faculty of Veterinary Medicine, Department of Parasitology, 36100 Kars, Turkey.

Correspondence: Salah Bouamer.

Tel. : $33(0) 468662187$ - Fax : $33(0) 468662281$.

E-mail : bouamer@univ-perp.fr
}

of the genus Mehdiella.

\section{MATERIALS AND METHODS}

T The nematodes were recovered from Testudo graeca Linneaus, 1758, collected in Morocco by S. Bouamer, from Testudo hermanni Gmelin, 1789, collected in Spain by Dr Carlos Feliu 
(University of Barcelona), from $T$. hermanni Gray, 1844 collected by Dr Annie Petter (coll. n ${ }^{\circ} 157$ Q, Muséum National d'Histoire Naturelle, Paris) and from Testudo horsfieldii Gray, 1844 of Iran collected by Dr Annie Petter (coll. n ${ }^{\circ} 64$ Q, Muséum National d'Histoire Naturelle, Paris). The nematodes of Pyxix arachnoides Bell, 1827 were collected by Dr Annie Petter (coll. $\mathrm{n}^{\circ} 82$ Q, Muséum National d'Histoire Naturelle, Paris). Nematodes were preserved in $70 \%$ ethanol before being cleared with lactophenol for study. Nematodes were prepared for SEM by dehydrating them in progressive ethanol concentrations up to absolute ethanol. Residual humidity was extracted to the critical point (M scope 500). The scan- ning electron microscope used was a Hitachi S 520 under $20 \mathrm{KV}$. Measurements are given in micrometers unless otherwise stated.

\section{RESULTS}

\section{MeHDiella CRISTATA PeTter, 1966}

\section{Redescription (Figs 1-6)}

General: Middle-sized body with lateral alae, straight in females, curved ventrally in males. Oesophagus thin and elongate. The cuticle forms in the anterior end series of vesicular rings.
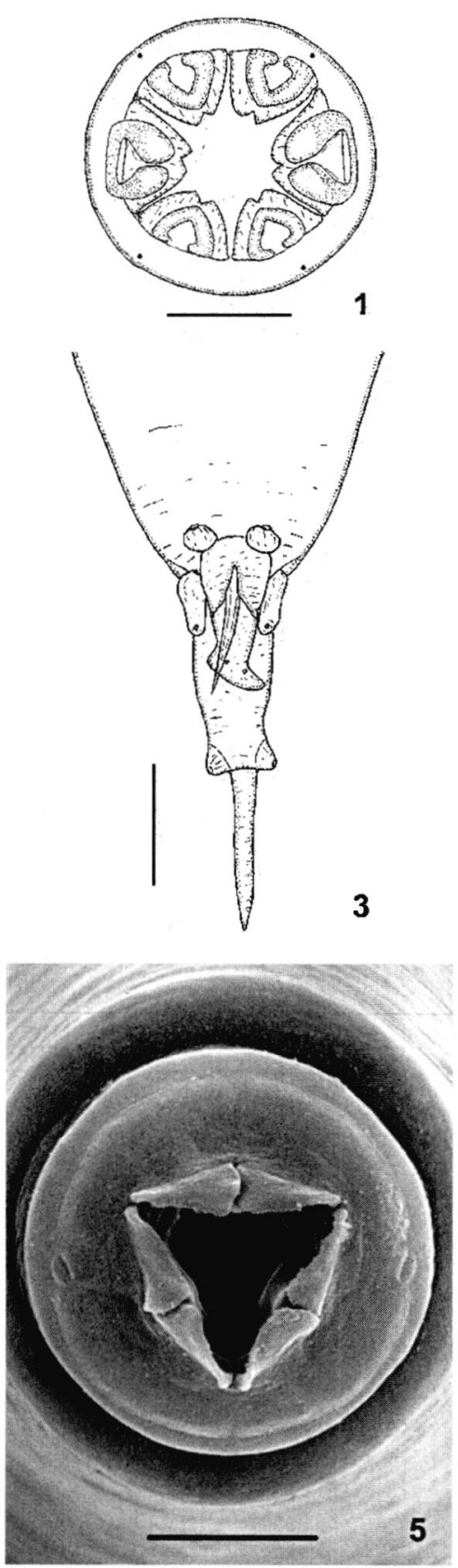
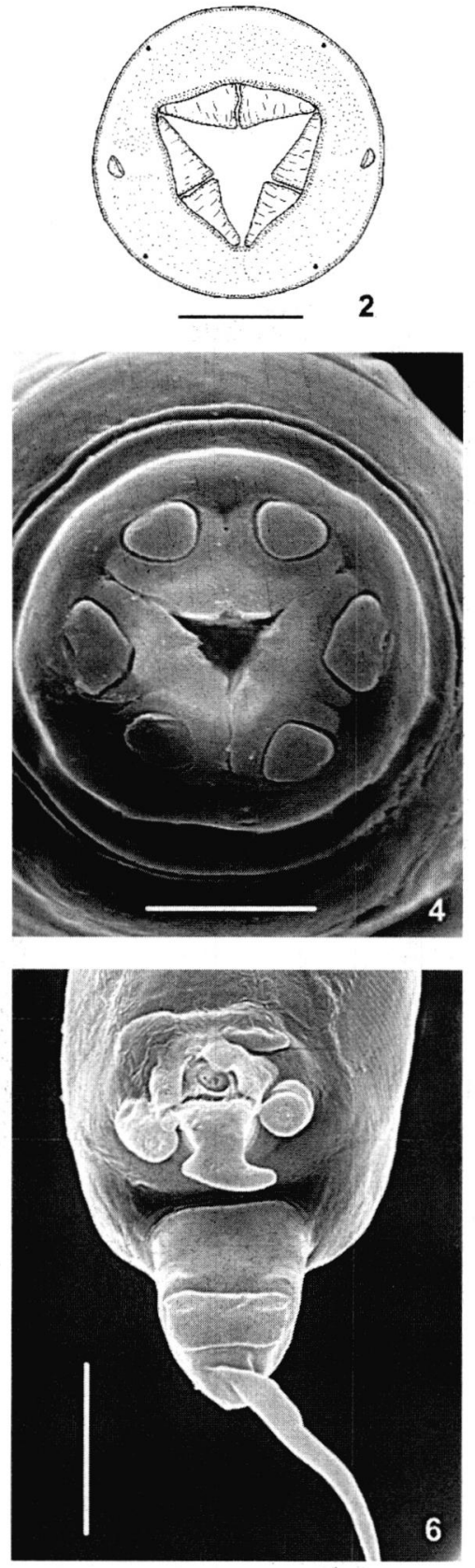

Figs 1-3. - Mehdiella cristata. 1. Cephalic end, en face of female. 2. Cephalic end, en face of male. 3. Caudal extremity, ventral view of male. Scale-bars: $1,2,8 \mu \mathrm{m} ; 3,30 \mu \mathrm{m}$.

Figs 4-6. - Mebdiella cristata. Scanning electron micrograph (SEM). 4. Cephalic end of female. 5. Cephalic end of male. 6. Caudal extremity of male, ventral view. Scale-bars: 4 , $8 \mu \mathrm{m} ; 5,10 \mu \mathrm{m} ; 6,20 \mu \mathrm{m}$. 
Female: triangular oral opening with three transparent, simple large lips. Eight cuticularized pieces projecting without any nerve ending at the cephalic end, with four medio-lateral triangular shaped (two dorso-lateral and two ventro-lateral) and four lateral pieces, the two pieces of each side joined, so forming one large piece with two tiny humps. Sessile, external amphids situated at the external side of these two pieces. Cephalic sense organs formed by an outer circle consisting of four sub-lateral papillae, situated at the external side of the four dorso-lateral and ventro-lateral cuticularized pieces (the inner circle of nerve endings, not observed). Short buccal cavity armed with teeth.

Measurements of four specimens: length 3.75-4.00 (3.90) $\mathrm{mm}$. Maximum width 345-365 (350) near midbody. Nerve ring 247-255 (250) and excretory pore $1.435-1.455(1.470) \mathrm{mm}$ from anterior end. Oesophagus 1.112-1.210 (1.150) mm long. Tail 280-295 (289) long. Vulva $2.35-2.50(2.40) \mathrm{mm}$ from anterior end. Eggs asymmetrical, measuring $51 \times 121(49 \times 119-53 \times 124)$.

Male: body thinner than that of the female. The head is separated from the body by a constriction. Ventral side with several crests on cuticle. Triangular oral opening with six transparent and prominent, elongate lips bearing a pointed hyaline projection at internal side of each lip. Cephalic sense organs formed by an outer circle of four sub-lateral papillae, an inner circle of papillae not observed; sessile and external amphids. Eight elongate cuticularized pieces without any nerve ending, form a circle surrounding oral opening. Short buccal cavity armed with thre small simple teeth. Cloaca with two pairs of genital papillae: one elongate pre-anal, middle-sized pair, and one long and pedunculate post-anal pair of papillae, each papilla with one nipple; two lateroventral pairs of papillae on the tail. Long, slender and needle-shaped spicule. Two lobes of pre-anal membrane. Anterior anal lip formed by two tiny lobes; post-anal lip with one left branch and two ventral nipples. Long tail, with a long and robust caudal point, tiny caudal alae absent.

Measurements of four specimens: length 2.6-2.7 (2.68) mm, with maximum width 195-205 (200) near midbody. Nerve ring 195-200 (197) from anterior end. Excretory pore 850-862 (857 from anterior end. Oesophagus 790-810 (796) long. Tail 162-176 long. Spicule 165-172 (169) long.

Material examined: eight female specimens and five male specimens.

Host: Pyxix arachnoides Bell, 1827, Coll. $\mathrm{n}^{\circ} 82 \mathrm{Q}$, Muséum d'Histoire naturelle, Paris.

Site: large intestine.

Geographical region: Madagascar, collected by Dr Annie Petter.
Specimens deposited: three females and three males deposited at the Muséum National d'Histoire Naturelle, Paris: number $65 \mathrm{HG}$.

Remarks: our redescription gives new information on buccal structure of the female and male and caudal structure of male. Petter (1966) mentioned three lips in male and female, each lip of male having a slit in its middle. In our study males have six lips (Fig. 2). We have observed that the large cuticularized pieces forming one circle, described by Petter (1966) as papillae, are without any nerve ending. Petter (1966) mentioned two nipples on each post-anal papilla, the use of a scanning microscope allowed verification that the previously described two nipples are a simple nipple, which is confirmed by optical observation. Finally, our redescription gives a new description of pre-anal membrane and of post-anal lip. This formation is similar to that of $T$. conica Drasche, 1884 (see Bouamer \& Morand 2002), but differs by possessing a single branch while $T$. conica possesses two.

Sexual dimorphism is marked in the size of body, with the female longer and larger than the male, and by the cephalic end.

\section{MEHDIELLA STYLOSA (THAPAR, 1925)}

Synonyms: Mehdiella dubinini Skjabin et Schikhobalova, 1951, M. hamosa Forstner, 1960, M. cordata Forstner, 1960 by Petter (1966).

\section{Redescription (Figs 7-12)}

General: small sized body, tapering at the anterior end. Straight in females, slender and slightly curved ventrally in males. Head distinct from body. Transversely striated cuticle, striation less distinct at the anterior end. Thin and long oesophagus. Excretory pore situated behind the oesophageal bulb.

Female: middle-sized, spindle-shaped body. At the anterior end the cuticle forms two small vesicular swellings. Oral opening dodecagonal with three large and transparent lips and cuticle at cephalic end thick with four lightly prominent plates with winding lines; buccal cavity short without teeth. Cephalic sense organs consisting of an inner circle of six not prominent nerve endings, situated as follows: two laterodorsal, two latero-ventral and two lateral at level of amphids and an outer circle consisting of four sublateral not prominent nerve endings (each papilla situated on middle of the external side of each plate). Two internal and slightly prominent amphids. A crown formed by six pairs of symmetrical apical spines around the oral opening situated at level of inner circle of nerve endings: two lateral pairs situated at the level of amphids, two latero-ventral pairs and two laterodorsal pairs. Conical, robust and middle sized tail. 

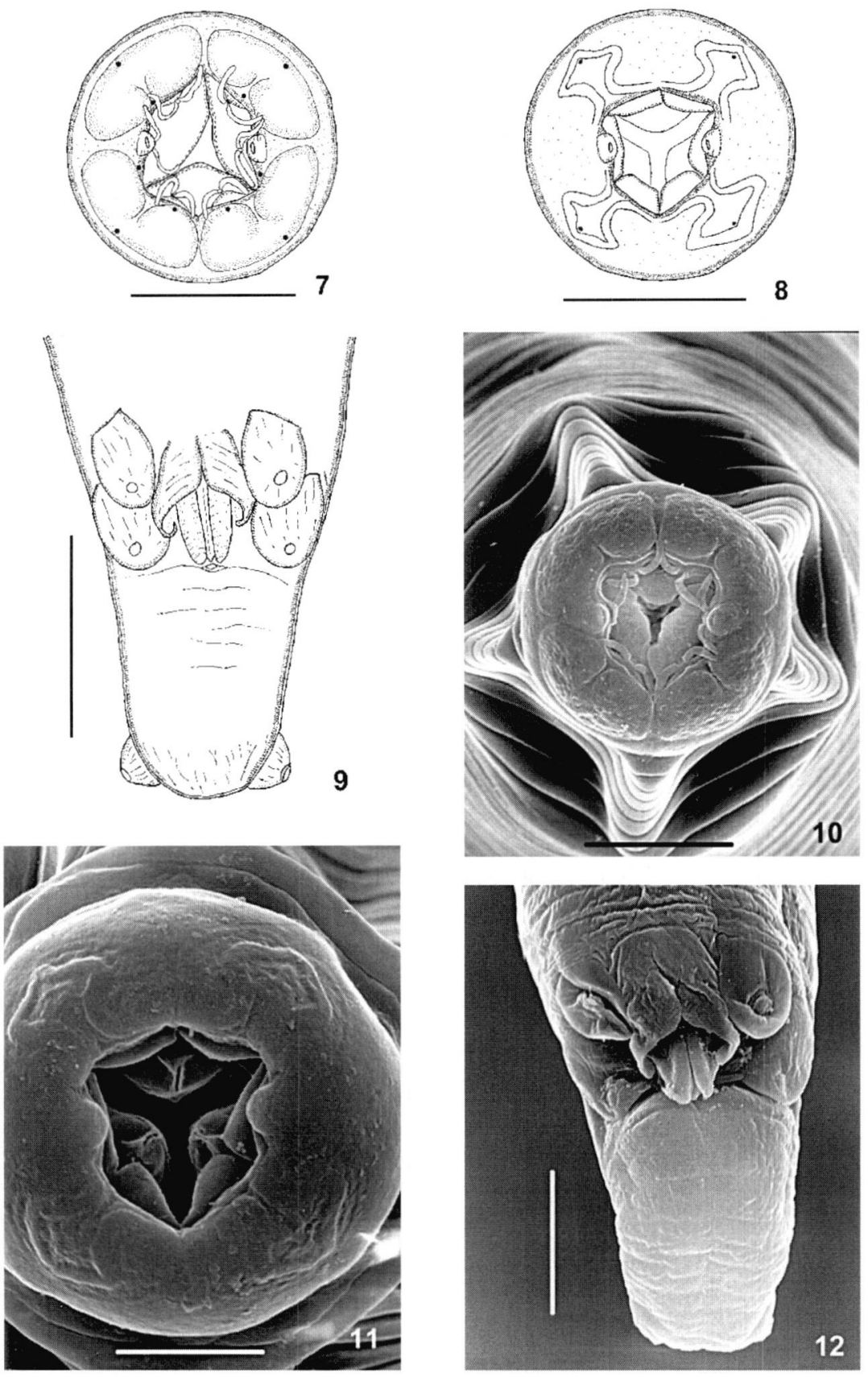

Figs 7-9. - Mehdiella stylosa. 7. Cephalic end en face of female. 8. Cephalic end, en face of male. 9. Caudal extremity, ventral view of male. Scale-bars: 7, 9, $20 \mu \mathrm{m} ; 8,15 \mu \mathrm{m}$.

Figs 10-12. - Mehdiella stylosa. Scanning electron micrograph (SEM). 10. Cephalic end of female. 11. Cephalic end of male. 12. Caudal extremity of male, ventral view. Scale-bars: 10 , $20 \mu \mathrm{m} ; 11,12,10 \mu \mathrm{m}$
Measurements of four specimens: length 4.80-5 (4.9) mm. Maximum width 290-305 (297) near midbody. Nerve ring 195-202(198) and excretory pore 1.50-1.59 (1.55) $\mathrm{mm}$ from anterior end. Oesophagus 1.25-1.33 (1.30) $\mathrm{mm}$ long. Tail 345-355 (348) long. Vulva 2.883.01 (3) $\mathrm{mm}$ from anterior end. Eggs asymmetrical, measuring $69 \times 110(67 \times 108-70 \times 111)$.

Male: smaller and thinner than female. Hexagonal oral opening bordered by six transparent and thin lips, two laterals, two sub-dorsal and two sub-ventral. Cephalic sense organs consisting of an outer circle of four sublateral papillae, an inner circle of papillae not observed. Two lateral prominent amphids. Short buccal cavity armed with three triangular-shaped teeth at the anterior end; each tooth formed by three cuticularized pieces (same shape as the teeth of Tachygonetria robusta (Drasche, 1884) (see Bouamer \& Morand, 2002). Two pairs of genital papillae: one elongated preanal pair and one elongated post-anal pair; one lateroventral pair of caudal papillae. Pre-anal membrane with two large lobes. Anterior lip of the anus formed by two robust and curved lobes; posterior lip conical-shaped with two lateral nipples. Fork-shaped spicule with two branches, the ventral branch shorter than the dorsal. Tail not truncate and curved with a robust and short point; tiny caudal alae present. 
Measurements of four specimens: Length 2.40-2.45 (2.41) $\mathrm{mm}$, with maximum width 145-152 (148) near midbody. Nerve ring 95-100 (97) from anterior end. Excretory pore 945-955 (949) from anterior end. Oesophagus 689-697 (693) long. Tail 37-42 (39) long. Spicule 50-55 (53) long.

Material examined: 30 female specimens and 25 male specimens.

Host: Testudo graeca Linneaus, 1758, Testudo hermanni Gmelin,1789.

Site: large intestine.

Geographical region: Settat, Morocco, $32^{\circ} 30^{\prime} 45^{\prime \prime} \mathrm{N}$, $7^{\circ} 45$ ' 30" W, 22 July 1999, collected by S. Bouamer. South Catalona, Spain, longitude $2^{\circ} 11^{\prime} 17^{\prime \prime} \mathrm{E}, 41^{\circ} 23^{\prime}$ 14" N, 17 December, 1993 by Dr C. Feliu.

Specimens deposited: four females and four males from Testudo graeca, deposited at the Muséum National d'Histoire Naturelle, Paris: number 66 HG.

Remarks: Mehdiella stylosa is distributed only in the Palaearctic Region in Testudo graeca from Europe, North Africa, Turkey, Afghanistan and Iran (Thapar 1925; Ryšavć, 1958; Forstner, 1960; Petter, 1962, 1966 and Roca et al., 1988). In Testudo graeca and T. horsfieldii from Dagestan, Kazakhstan and Tadzhikistan (Dubinina 1949, Sharpilo 1976). Finally Petter (1966) and Johnson (1973) cited this species in T. hermanni respectively from Italy and Albania.

Our redescription gives new information on cephalic structure in both sexes and caudal structure in the male of Mehdiella stylosa, there are two pairs of elongate genital papillae, one pair pre-anal, and one pair postanal, Petter (1962) mentioned three genital pairs: one pair pre-anal, one pair ad-anal and one pair post-anal. Sexual dimorphism is marked in the presence of apical spines in female, and in the number of cephalic lips.

\section{MeHDielLa DOLLFusi PetTer, 1966}

Redescription (Figs 13-18)

General: small body, oesophagus thin and long; tail robust and conical in females, short and curved dorsally in the males. Two slightly prominent amphids. Excretory pore situated behind the oesophageal bulb.

Female: at the anterior end the cuticle forms two small vesicular swellings. Oral opening dodecagonal with three large, transparent lips and cuticle at cephalic end thick with four slightly prominent plates with winding lines. Short buccal cavity, with three robust teeth. Cephalic sense organs formed by an outer circle of four sub-lateral papillae (each papilla situated on middle of the external side of each plate), an inner circle of papillae not observed. A crown formed by six pairs of symmetrical and rectangular apical spines. Long tail.
Measurements of four specimens: length 2.68-2.75 (2.7) mm. Maximum width 198-205 (201) near midbody. Nerve ring 197-200 (199) and excretory pore 0.995$1(0.98) \mathrm{mm}$ from anterior end. Oesophagus 0.998 1.01(1.001) mm long. Tail 115-122 (119) long. Vulva $1.6-1.67$ (1.63) $\mathrm{mm}$ from anterior end. Eggs asymmetrical, measuring $51 \times 121(49 \times 119-53 \times 124)$.

Male: small body, tail curved; hexagonal oral opening with six transparent lips of conical shape and cuticle at cephalic end thick with four slightly prominent plates with winding lines. Cephalic sense organs formed by an inner circle consisting of six non prominent nerve endings (difficult to observe): two latero-dorsal, two latero-ventral and two lateral, and by an outer circle of four sub-lateral papillae; large, sessile and slightly prominent amphids. Short buccal cavity armed with three robust teeth, each tooth formed by three cuticularized pieces (Fig. 17). Two pairs of genital papillae: one rosette-shaped pre-anal pair and one elongated post-anal pair; latero-ventral pair of caudal papillae. Short pre-anal membrane with 14 lobes, the two external with a globular shape. Anterior lip of the anus formed by two robust lobes; posterior lip projecting in conical shaped form with two lateral nipples. Fork-shaped spicule with two branches almost of same length (Fig. 18). Tiny caudal alae present.

Measurements of four specimens: length 2.08-2.1 (2.95) mm, with maximum width 145-151 (147) near midbody. Nerve ring 98-102 (99) from anterior end. Excretory pore 840-850 (847) from anterior end. Oesophagus 695-700 (698) long. Tail 55-61 (58) long. Spicule 45-49 (48) long.

Material examined: 18 female specimens and 12 male specimens.

Host: Pyxix arachnoides Bell, 1827, 82 Q, Muséum National d'Histoire Naturelle, Paris.

Site: large intestine.

Geographical region: Madagascar, collected by Dr A. Petter.

Specimens deposited: four females and four males deposited at the Muséum National d'Histoire Naturelle, Paris: number $67 \mathrm{GH}$.

Remarks: Mebdiella dollfusi is distributed only in the Ethiopian region in Pyxix arachnoides and Astrochelys radiata (Shaw, 1802) from Madagascar (Petter 1966). Our redescription gives new information on cephalic structure in both sexes and caudal structure in male. We did not find any formation in the male which resembles the apical spines in the female. Two pairs of elongate genital papillae are observed in the male, one pair pre-anal, and one pair post-anal. Petter (1962) mentioned three genital pairs: one pair pre-anal, one pair ad-anal and one pair post-anal. Sexual dimorphism 

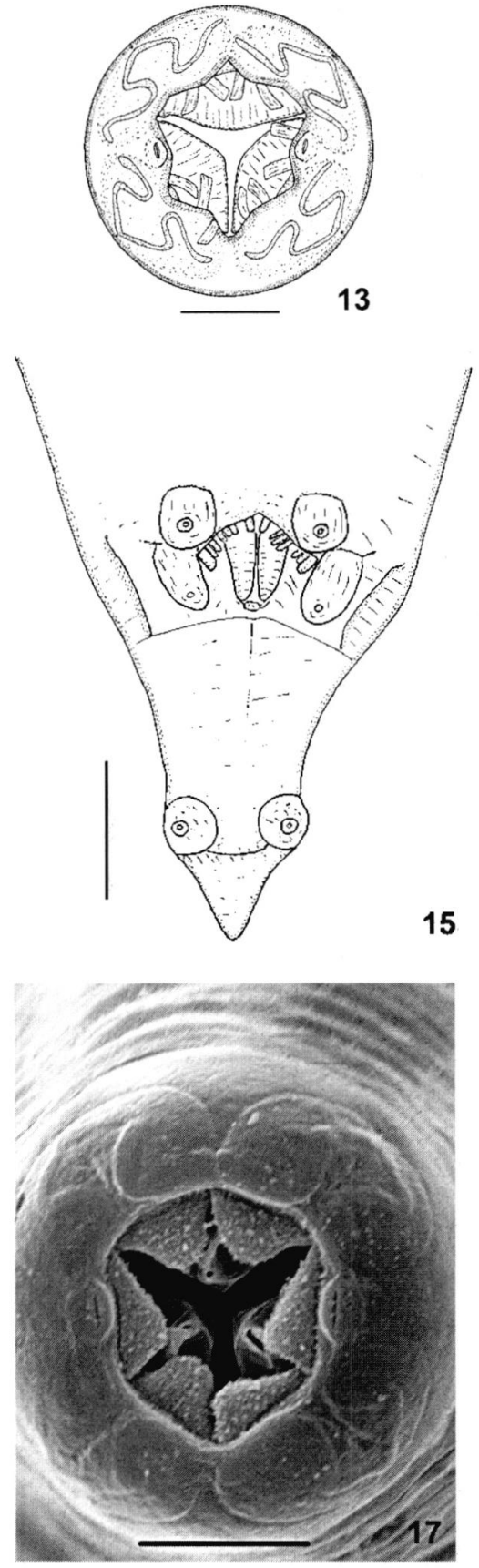
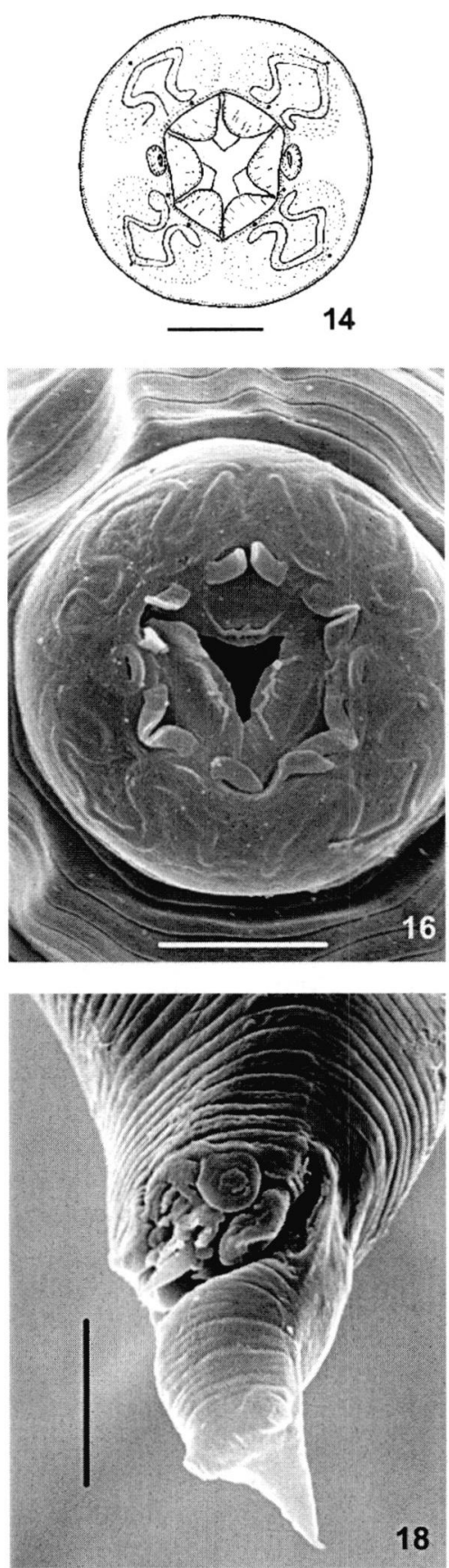

Figs 13-15. - Mehdiella dollfusi. 13. Cephalic end, en face of female. 14. Cephalic end, en face of male. 15. Caudal extremity, ventral view of male. Scale-bars: 13, 14, $8 \mu \mathrm{m} ; 15$, $12 \mu \mathrm{m}$.

Figs 16-18 - Mehdiella dollfusi. Scanning electron micrograph (SEM). 16. Cephalic end of female. 17. Cephalic end of male. 18. Caudal extremity of male, ventral view. Scale-bars: 16$18,10 \mu \mathrm{m}$ is marked in the presence of the apical spines in female and the number of cephalic lips.

\section{MEHDIELLA UNCINATA (DRASCHE, 1884)}

Synonyms: Oxyuris uncinata Drasche, 1884; O. inflata Drasche, 1884 (see Yorke \& Maplestone, 1926); O. albanica Stossich, 1898 (see Yorke \& Maplestone, 1926); Tachygonetria uncinata (Drasche, 1884); T. inflatocervix Akhtar, 1937 (see Petter, 1966); Mehdiella inflata Forstner, 1960 (see Petter, 1966); M. uncinata albanica Johnson, 1973 (see Baker, 1987).
Redescription (Figs 19-24)

General: body thick, medium-sized, straight in female and slightly curved in male. Cuticle thick, transversely striated and forming at the anterior end vesicular swellings, differing by the size and the number between sexes; head distinct with cuticle not striated. Oesophagus relatively short. Excretory pore situated behind bulb.

Female: at anterior end the cuticle forms three vesicular swellings, the first of small size, the third larger than the first, the second is largest, the form and the 

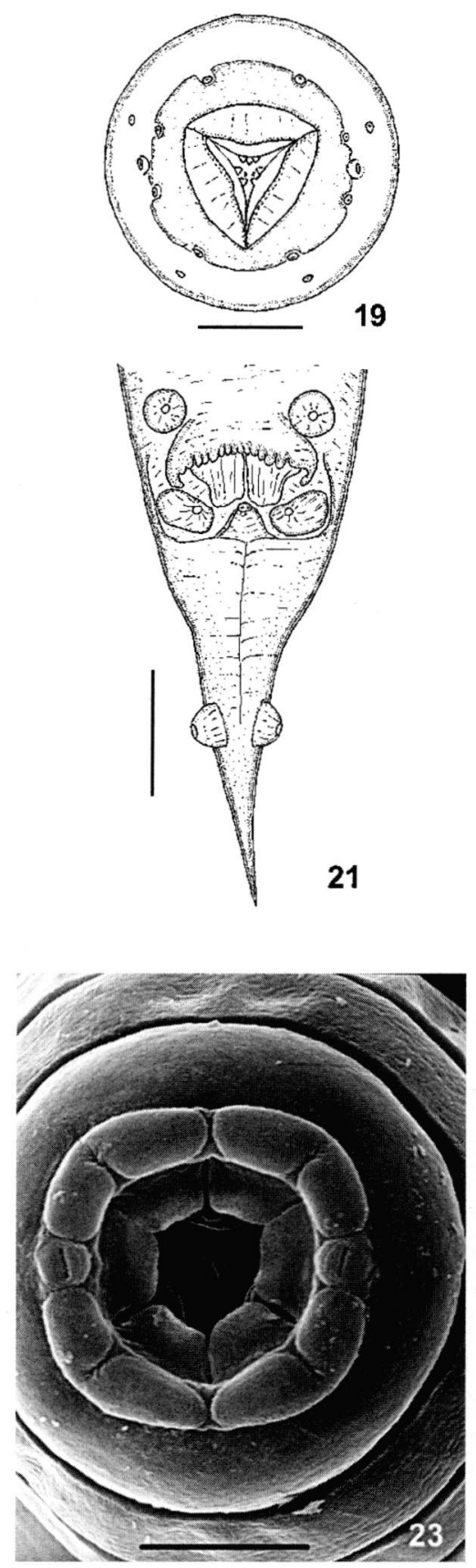
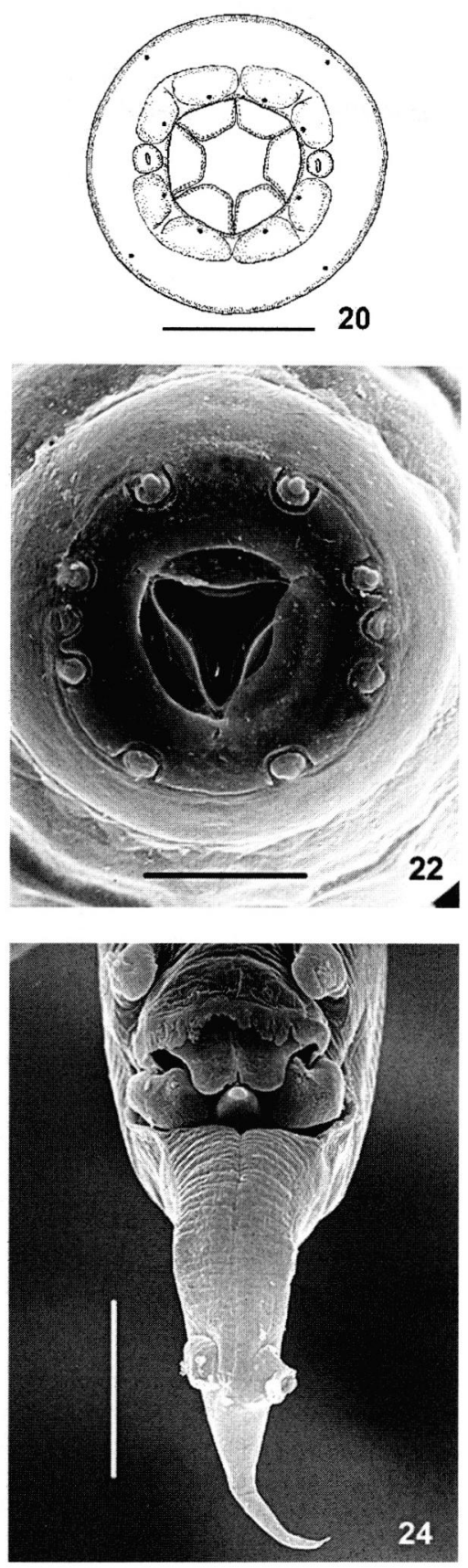

Figs 19-21. - Mebdiella uncinata. 19. Cephalic end, en face of female. 20. Cephalic end, en face of male. 21. Caudal extremity, ventral view of male. Scale-bars: $19-21,8 \mu \mathrm{m}$.

Figs 22-24. - Mebdiella uncinata. Scanning electron micrograph (SEM). 22. Cephalic end of female. 23. Cephalic end of male. 24. Caudal extremity of male, ventral view. Scale-bars: 22 , $24,20 \mu \mathrm{m} ; 23,10 \mu \mathrm{m}$. size of the second vesicular swelling varying slightly according to individuals. Oral opening circular, surrounded by three transparent and simple lips. Buccal cavity short, oesophagus armed with nine small teeth situated as follows: six at anterior end with two teeth of different size on each lobe of oesophagus, three teeth situated about seven $\mu \mathrm{m}$ of the anterior end, with one tooth on each sector of oesophagus. Cephalic sense organs consisting of an inner circle of eight nerve endings on prominent papillae, four on the lateral side, two on the ventral side and two the on dorsal side. The outer circle not observed; two large prominent lateral amphids. Tail robust, long and conical.
Measurements of four specimens: Length 5.90-6 (5.95) mm. Maximum width 390-398 (395) near midbody. Nerve ring 350-356 (354) and excretory pore 1.6-1.615 (1.607) $\mathrm{mm}$ from anterior end. Oesophagus 1.27-1.285 (1.8) $\mathrm{mm}$ long. Tail 348-355 (351) long. Vulva 3.24-3.3 (3.26) $\mathrm{mm}$ from anterior end. Eggs asymmetrical, measuring $81 \times 140(78 \times 138-82 \times 141)$.

Male: at the cephalic end cuticle forming several (at least seven), small vesicular swellings (the second is largest, same size as the female), situated just behind the head. Oral opening sub-hexagonal, surrounded by six transparent and simple lips. Buccal cavity short, oesophagus not armed with teeth at anterior end. Cephalic 
sense organs consisting of inner circle of eight nerve endings, on prominent papillae, four on the lateral side, two on the ventral side and two on dorsal side. The outer circle of four large submedian papillae, and two large prominent lateral amphids. Cuticle thick at cephalic end with four prominent cuticularized plates without nerve endings surrounding the lips at the same level as the amphids, each plate formed by two prominent elongated bumps; this plates situated as follows: two later-dorsal and two latero-ventral. Cloaca with two elongate pairs of genital papillae: one pair pre-anal and one pair post-anal. Pre-anal membrane present with ten lobes. Anterior lip of anus with two robust, and trapeziform lobes, the extremity of spicule visible between them, posterior lip conical-shaped with two lateral nipples. Spicule short, needle-shaped. Long, not truncate and curved dorsally tail with two latero-ventral caudal papillae situated at level of the $2 / 3$ of tail and with a robust and long point. Tiny caudal alae present. Measurements of four specimens: length 3.12-3.15 (3.143) $\mathrm{mm}$, with maximum width 250-260 (256) near midbody. Nerve ring 222-230 (227) from anterior end. Excretory pore 901-9.07 (9.05) from anterior end. Oesophagus 782-790 (786) long. Tail 112-117 (114) long. Spicule 97-101 (98) long.

Material examined: 50 female specimens and 40 male specimens.

Host: Testudo graeca Linneaus, 1758, Testudo hermanni Gmelin, 1789 and Testudo horsfieldii (Gray, 1844)

Site: large intestine.

Geographical region: Settat, Morocco, $32^{\circ} 30^{\prime} 45^{\prime \prime} \mathrm{N}$, 7045 ' 30" W, 22 July 1999, collected by S. Bouamer. South Catalona, Spain, longitude $2^{\circ} 11^{\prime} 17^{\prime \prime}$ E, $41^{\circ} 23^{\prime}$ 14" N, 17 December, 1993, collected by Dr C. Feliu and Testudo horsfieldii from Iran, 64 Q Muséum National d'Histoire Naturelle, Paris.

Specimens deposited: four females and four males from Testudo graeca, deposited at the Muséum d'Histoire Naturelle (Paris): number 68 HG.

Remarks: this species is distributed only in the Palaearctic region in Testudo graeca from Europe, North Africa, Afghanistan and Iran (Drasche, 1884, Stossich, 1898, Seurat, 1918, Thapar, 1925, Ryšavć, 1958, Forstner, 1960, and Petter, 1961, 1966), in Testudo kleinmanni Lortet, 1833 in Egypt (Baylis, 1923), in Testudo borsfieldii in Turkestan and Iran (Rees, 1935, Akhtar, 1937, Dubinina, 1949 and Petter, 1966), Volga Delta and Caspian steppe (Markov et al., 1962), and Dagestan Sharpilo,1976); and T. hermanni in Albania (Johnson, 1973) and in Italy (Petter, 1966).

Our redescription gives new information on buccal and caudal structure of Mehdiella uncinta. In female three transparent lips surrounding the oral opening, Petter (1962) citing six lips. Buccal cavity armed with teeth in females (nine teeth). Four cuticularized plates surrounding the lips are observed in the male. Similar formations are observed in Tachygonetria dentata Wedl, 1862, see Bouamer \& Morand (2002). Finally there are two pairs of elongate genital papillae in the male, one pair pre-anal, and one pair post-anal.

Sexual dimorphism is marked, with the female longer and larger than the male and with a different structure of cephalic end between sexes. The buccal cavity is armed with teeth only in the female.

\section{DISCUSSION}

ccording to our redescriptions, Mehdiella doll-
fusi and $M$. stylosa show important differences:
in males of $M$. dollfusi large cephalic lips with a conical internal side, whereas in males of $M$. stylosa small cephalic lips with a straight internal side. The apical spines are robust and short in $M$. dollfusi whereas in $M$. stylosa they are thin and long. In $M$. dollfusi the fork-shaped spicule has two branches of almost the same length, whereas in $M$. stylosa the ventral branch is shorter than the dorsal branch. The shape of pre-anal membrane shows a real difference in males of the two species: in $M$. dollfusi, the membrane is divided into several tiny lobes, whereas in M. stylosa this membrane is composed of two large overlapping lobes. The shape of pre-anal lip is also different, straight in $M$. dollfusi and curved in M. stylosa. In the female of $M$. dollfusi, the vulva is prominent whereas not so in $M$. stylosa. Finally the oesophagus is longer in $M$. dollfusi than in M. stylosa. We propose to raise these two sub-species to level of species.

Mehdiella cristata shows a great morphological divergence with the other species of the genus Mehdiella; the presence of a lateral alae, a prominent genital cone in males, the structure of cephalic end similar to structure observed in the genus Thelandros Wedl, 1862, (see Petter, 1966 and Caballero, 1968) and the position of the caudal papillae and the shape of the tail. In males of all the other species of the genus Mebdiella, tiny caudal alae are present (Bouamer et al., 2001b), but absent in M. cristata; a similar structure is observed in some species of the genus Thelandros, see Caballero (1968). These observations question the position of M. cristata among the genus Mehdiella.

The oxyurid parasites of herptiles is a group with complex morphological structures. Our new observations using light microscope and SEM, allow us to improve descriptions and reveal unnoticed characters, which may have a potential interest in systematic and phylogenetic reconstruction.

The apical and caudal end morphology allows us to distinguish four groups in the genus Mehdiella. The first group is formed by Mehdiella stylosa, M. dollfusi and 
M. petterae. These species seem to be related by sharing the following characters in the males: the number and similarity of the shape of the cephalic lips, the presence of a buccal cavity armed with teeth and the shape of the tail. The second group contains M. microstoma and $M$. longissima. They resemble by the shape of the bodies in both sexes and by shape of caudal end in the male. They differ by the shape of the mouth in the female and the length of the oesophagus. In M. microstoma the oral opening in the female is longitudinal with unequal lips, whereas in M. longissima the oral opening is triangular and the oesophagus is short. $M$. uncinata and $M$. grasse $i$ are included in the third group. The shape of caudal tail in the male of M. uncinata resembles that of $M$. grassei (see the description of Petter, 1966), but these two species differ by the structure of cephalic end, with four prominent cuticularized plates in the male of M. uncinata, absent in M. grassei. The fourth group is formed by one species $M$. cristata.

\section{KEY TO THE SPECIES OF THE GENUS MEHDIELLA}

This includes Mehdiella longissima Petter, 1966 and M. grassei Petter, 1966, although not redescribed here.

1 Vesicular swellings in anterior extremity present...2 Vesicular swellings in anterior extremity absent....6

2 Spicule extremity simple .......................................... 3 Spicule with fork-shaped extremity ........................ 4

3 Post-anal lip with one left branch, buccal cavity armed with three teeth........... cristata Petter, 1966 Post-anal lip globular, buccal cavity of female armed with nine teeth................. uncinata (Drasche, 1884)

4 Tail straight................. petterae Bouamer et al., 2001 Tail curved dorsally ................................................

5 Pre-anal membrane with two large lobes........... stylosa (Thapar, 1949)

Pre-anal membrane with several tiny lobes...M dollfusi Petter, 1966

6 longitudinal oral opening. M. microstoma (Drasche, 1884)

Triangular oral opening

7 Short oesophagus and oral opening in the male with three lips .......................... longissima Petter, 1966 Long oesophagus and oral opening in the male with six lips M. grassei Petter, 1966

\section{ACKNOWLEDGEMENTS}

W e are indebted to Dr Annie Petter (Muséum National d'Histoire Naturelle, Paris) for generously providing the Malagasy Nematodes.
We thank anonymous referees for constructive suggestions and comments, which greatly improved the final form of the manuscript.

\section{REFERENCES}

AKHTAR S.A. Report on some nematode parasites of Kabul, with descriptions of new species. Proceedings of Indian Academic of Science, 1937, 6, 263-273.

BAKER M.R. Synopsis of the Nematoda parasitic in amphibians and reptiles. Memorial University of Newfoundland, Occasional Papers in Biology, 1987, 1, 1-325.

BayLIS H.A. Report on a collection of parasitic nematodes, mainly from Egypt. II. Oxyuridae. Parasitology, 1923, 15, 14-23.

Bouamer S. \& Morand S. Oxyuroids of Palearctic Testudinidae: new definition of the genus Thaparia Ortlepp, 1933 (Nematoda: Pharyngodonidae), redescription of T. thapari thapari, and descriptions of two new species. Comparative Parasitology, 2000, 67, 169-180.

Bouamer S., Morand S. \& Bourgat R. Oxyuroids of Palearctic Testudinidae - New definition of the genus Alaeuris Seurat, 1918 (Nematoda: Pharyngodonidae), redescription of Alaeuris numidica (Seurat, 1918). Journal of Parasitology, 2001a, 87 (1), 128-133.

Bouamer S., Morand S. \& Bourgat R. Redescription of Mehdiella microstoma and description of Mehdiella petterae sp. n., with a new definition of the genus Mebdiella Seurat, 1918 (Nematoda: Pharyngodonidae). Folia Parasitologica, 2001b, 48, 132-138.

Bouamer S. \& MORAND S. Description of T. combesi $\mathrm{n}$. sp. and redescriptions of four species of the genus Tachygonetria Wedl, 1862 (Nematoda: Pharyngodonidae), with a new diagnosis of the genus. Systematic Parasitolgy, 2002, 53, 121-139.

CABAllero G.R. Contribution à la connaissance des Nématodes de Sauriens Malgaches. Annales de Parasitologie Humaine et Comparée, 1968, 43 (2), 149-200.

DRASCHE R.V. Nematoden aus Testudo graeca. Verhandlungen der Zoologisch-Botanischen Gesellschaft in Wien, 1884, 33, 325-330.

DuBinina M.H. Ecological studies on the parasite fauna of the Testudo horsfieldii Gray from Tadjikistan. Parazitologicheskii Sbornik Zoologicheskogo Instituta AN SSSR, 1949, 11, 61-97 (In Russian).

FORSTNER M.J. Ein Beitrag zur Kenntnis parasitischer Nematoden aus greichischen Landschildroten. Zeitschrift für Parasitenkunde, 1960, 20, 1-22.

JoHnSon S. Some oxyurid nematodes of the genera Mehdiella and Thaparia from the tortoise Testudo hermanni. Folia Parasitologica, 1973, 20, 141-148.

Markov G.S., Ivanov V.P., Nikulin V.P. \& Chernobai V.F. Helminth parasites of reptiles from the Volga-Delta and Caspian steppe. Trudy Astrakhanskogo Zapovednika, 1962, 6, 145-172 (In Russian).

Petter A.J. Redescription et analyse critique de quelques espèces d'Oxyures de la tortue grecque (Testudo graeca L.) 
Diversité des structures céphaliques (II). Annales de Parasitologie Humaine et Comparée, 1962, 37, 140-152.

Petter A.J. Équilibre des espèces dans les populations de Nématodes parasites du côlon des Tortues terrestres. Mémoires du Muséum National d'Histoire Naturelle, Nouvelle Série, série A, Zoologie, 1966, 39, 1-252.

REes F.G. Two new species of Tachygonetria from the Indian tortoise, Testudo horsfieldii Gray. Proceedings of the Zoological Society of London, 1935, 3, 599-603.

Roca V, Galeano M \& Garcia Addel G. Parasitic nematodes from the Mediterranean tortoise Testudo graeca Linnaeus, 1758 (Reptilia: Testudinidae) in Spain. Revista Iberica de Parasitologia, 1988, 48, 268-274.

RYšAVÝ B. Contribution to the knowledge of nematodes of imported Testudo graeca. Československá Parasitologie, 1958, 5, 178-183 (In Czech).

Seurat L.G. Contribution à l'étude de la faune parasitaire de la Tunisie. Nématodes. Archives de l'Institut Pasteur de Tunis, 1918, 10, 243-275.

SHARPILO V.P. Parasitic worms of the reptiles of the USSR fauna. Systematics, chorology, biology. Kiev: Naukova Dumka, 1976, 287 p. (In Russian).

STossich M. Saggio di una elmintologica di Trieste. Programma della Civica Scuola Reale Superiore. Trieste, 1898, 162 p.

THAPAR G.S. Studies on the oxyurid parasites of the reptiles. Journal of Helmintology, 1925, 3, 83-150.

YORKE W. \& MAPLESTON P.A. The nematode parasite of vertebrates. London, 1926, 536 p.

Reçu le 26 février 2003

Accepté le 22 septembre 2003 